\title{
Management of colorectal cancer explains differences in 1-year relative survival between France and England for patients diagnosed 1997-2004
}

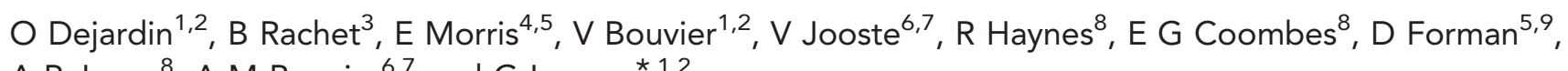
A P Jones ${ }^{8}$, A M Bouvier ${ }^{6,7}$ and G Launoy ${ }^{\star 1,2}$

${ }^{1}$ U1086 INSERM UCBN, Cancers \& Preventions, Caen, France; ${ }^{2}$ University Hospital of Caen, Caen, France; ${ }^{3}$ Cancer Research UK Cancer Survival Group, London School of Hygiene and Tropical Medicine LSHTM, London WC1E 7HT, UK; ${ }^{4}$ Cancer Epidemiology Group, Leeds Institute of Molecular Medicine, University of Leeds, St James's University Hospital, Level 6, Bexley Wing, Leeds LS9 7TF, UK; ${ }^{5}$ Northern and Yorkshire Cancer Registry \& Information Service (NYCRIS), St James's University Hospital, Level 6, Bexley Wing, Leeds LS9 7TF, UK; ${ }^{6}$ Digestive Cancer Registry of Burgundy INSERM U866, France Dijon F-21079, France; ${ }^{7} \mathrm{CHU}$, Dijon F21079, France; ${ }^{8}$ School of Environmental Sciences, University of East Anglia, Norwich, UK and ${ }^{9}$ International Agency for Research against Cancer (IARC), Section of Cancer Information, Lyon, France

Background: Few international population-based studies have provided information on potential determinants of international disparities in cancer survival. This population-based study was undertaken to identify the principal differences in disease characteristics and management that accounted for previously observed poorer survival in English compared with French patients with colorectal cancer.

Methods: The study population comprised all cases of colorectal cancer diagnosed between 1997 and 2004 in the areas covered by three population-based cancer registries in France and one in England $(N=40613)$. To investigate the influence of clinical and treatment variables on survival, we applied multivariable excess hazard modelling based on generalised linear models with Poisson error.

Results: Poorer survival for English patients was primarily due to a larger proportion dying within the first year after diagnosis. After controlling for inter-country differences in the use of chemotherapy and surgical resection with curative intent, country of residence was no-longer associated with 1-year survival for advanced colon cancer patients (excess hazard ratio $(E H R)=0.99$ (0.92-1.01), $P=0.095)$ ). Longer term (2-5 years) excess hazards of death for colon and rectal cancer patients did not differ between France and England.

Conclusion: This study suggests that difference in management close to diagnosis of colon and rectum cancer is related to differences in survival observed between France and England. All efforts (collection and standardisation of additional variables such as co-morbidity) to investigate the reasons for these disparities in management between these two countries, and more generally across Europe, should be encouraged. 
Survival for patients with colorectal cancer varies notably between European countries. As reported by the CONCORD study (Coleman et al, 2008) in 2008, 5-year relative survival for colorectal cancer in France was 55.6\% for men and 61.5\% for women, which constituted the highest survival in Western Europe and second best in the world for women. By contrast, in England 5year relative survival was worse than in comparable European countries at $42.3 \%$ for men and $44.7 \%$ for women. The improvement in 5-year relative survival between 1988-1990 and 2000-2002 was comparable in both countries $(+10.2 \%$ in France $v s+10.4 \%$ in England) (Brenner et al, 2011). Under the scenario of equal survival in England compared with the mean European 5year survival, between 6600 and 7500 deaths would have been avoided each year for patients diagnosed between 1985 and 1999 (Abdel-Rahman et al, 2009).

Some authors have suggested that these international disparities in cancer survival, in particular the poorer survival in England, may not be due to actual differences in survival, but rather due to differences in cancer registration modalities and quality (Beral and Peto, 2010). However, a recent study highlighted that, even under the hypothesis of extreme incorrect registration (either date of recurrence instead of date of diagnosis or under-registration of long survivors), differences in cancer registration would explain very little of the observed disparities in survival (Woods et al, 2011). Another study suggested that the magnitude of error in survival time due to incorrect case completeness was $<1 \%$ for patients diagnosed with colorectal cancer in England (Møller et al, 2011). Moreover, registries included in the EUROCARE studies are broadly comparable in terms of registration methods, especially in terms of microscopic verification and the prevalence of death certificate only records (Berrino et al, 2007).

The reasons behind the international differences in survival are not well understood and many factors have been argued as potentially influential. For example, there is some evidence to show that the lower survival in England compared with Scandinavian countries is due to a high number of deaths, particularly among elderly patients, in the first 3 months following diagnosis (Engholm et al, 2007; Folkesson et al, 2009; Morris et al, 2011). This would suggest that a greater proportion of the population in England present with rapidly fatal disease than elsewhere in Europe. This may be due to more English cases presenting with advanced disease at diagnosis, concomitant morbidity or, perhaps, experiencing a different quality of care to those in other European countries (Gatta et al, 2010).

International comparisons of survival for patients with cancer are important for the planning and provision of national health services. However, with the notable exception of 'EUROCARE highresolution' studies (Gatta et al, 2000; Ciccolallo et al, 2005), very few international population-based studies have provided information on potential determinants of international disparities in cancer survival. The aim of this population-based study was to identify the principal differences in disease characteristics and cancer management that accounted for the difference in survival observed between France and England for patients with colorectal cancer.

\section{MATERIALS AND METHODS}

Population. The study population comprised all cases of colorectal cancer (ICD10: C18.0-C20.9) diagnosed between 1997 and 2004 in the areas covered by three population-based cancer registries in France (Calvados, Côte d'Or and Saône et Loire: 3\% of the whole national population of France) and one in England (the Northern and Yorkshire Cancer Registry Information Service (NYCRIS), which covers $13.3 \%$ of the national population) (Table 1). The completeness and data quality of the included registries are regularly assessed by the International Agency for
Research on Cancer (IARC) or by European Network of Cancer Registries (ENCR). The final population study included 40613 patients (7891 from France and 32722 from England). Over the period study, 919 patients in England had a 0-day survival (2.8\%) vs 18 out of 7891 (0.22\%) in France.

Data. Date of birth, sex and year of diagnosis were known for all patients. Topography was classified as right colon (C18.0, C18.1, C18.2, C18.3 and C18.4); left colon (C18.5, C18.6 and C18.7); unknown location of colon cancer (C18.8 and C18.9); rectosigmoid junction (C19.9) and rectum (C20.9) (Fritz et al, 2000). Stage was coded using Duke's classification: Duke's A: Limited to mucosa; Duke's B: Penetrating through muscularis propria; Duke's C: lymph nodes involved; 'Duke's D': a least one metastasis (Dukes, 1932). The unstaged category included: non-resected patients with no clinical evidence of metastases at diagnosis, resected patients but for whom the registry did not capture the stage, and patients who received potentially downstaging radiotherapy or chemoradiotherapy before surgery. Localised cancers were defined by Duke's A \& B and advanced cancers were defined by Duke's C \&D. Stage at diagnosis was unknown for almost 18\% and 7\% of English and French patients, respectively (these percentages are comparable to previous studies) (Jones et al, 2009).

Information was collected on the type of treatment: surgical resection with curative intent within 6 months since diagnosis (Coded as: yes or no), chemotherapy (yes or no) and radiotherapy (yes or no). Palliative chemotherapy and palliative radiotherapy were not recorded in NYCRIS. French registries captured information on all chemotherapy and radiotherapy administered irrespective of intent.

Survival time was defined as the time duration between the date of diagnosis and the earlier of date of death or date of last information about vital status or the end of the study period on 31 December 2008.

Statistical analysis. Estimation of up to 5-year relative survival was based on the Ederer-II approach using the user-written Stata command strs (Estimating and modelling relative survival, available at http://www.pauldickman.com/). To investigate the influence of clinical and treatment variables on survival, we applied multivariable excess hazard modelling based on generalised linear model with Poisson error (Dickman et al, 2004). EHR was calculated with 95\% confident intervals (Dickman et al, 2004). Time since diagnosis was split into intervals as following: 0-3 months, 3-6 months, 6 months-1 year, 1-2 years, 2-3 years and 4-5 years. To take into account the influence of treatment, survival analyses were then stratified according to cancer tumour site and stage. All analyses were computed using STATA 12.1 software (StataCrop LP, College Station, TX, USA) using a publicly available procedure (estimating and modelling relative survival, available at http://www.pauldickman.com/). In the absence of reliable information on the cause of death among the cancer patients, cancerrelated survival is commonly estimated by a relative survival approach that removes from the observed, all-cause mortality the expected ('background') mortality. Background mortality was provided by life tables stratified according to age, sex, year of diagnosis and administrative area (Government Office Region for England and 'Department' for France).

Multiple imputations by chained equations were performed to take into account missing values (Little and Rubin, 2002) (missing values are presented in Table 2). The imputation model incorporated the variables used in the analytical models (survival time, vital status, age, sex, topography, stage, year of diagnosis and treatments) as recently recommended (Nur et al, 2010). The imputation model was stratified according to country. Iterations were conducted to create 20 completed data sets, and the estimates were combined according to the Rubin rules (Rubin, 1987). Multiple imputation models were conducted using the STATA 12.1 module for imputation (StataCorp. 2011, Stata: Release 12, Statistical Software, College Station, TX, USA: 
Table 1. Patients diagnosed with colorectal cancer in two European countries between 1997 and 2004 ( $\mathbf{N}=40613$ )

\begin{tabular}{|c|c|c|c|c|c|c|c|c|c|}
\hline \multirow[b]{2}{*}{ Variables } & \multicolumn{2}{|c|}{$\begin{array}{l}\text { Calvados } \\
(N=2481)\end{array}$} & \multicolumn{2}{|c|}{$\begin{array}{l}\text { Côte d'Or } \\
(N=2329)\end{array}$} & \multicolumn{2}{|c|}{$\begin{array}{l}\text { Saone et Loire } \\
\quad(N=3081)\end{array}$} & \multicolumn{2}{|c|}{$\begin{array}{l}\text { England (NYCRIS) } \\
\qquad(N=32722)\end{array}$} & \multirow[b]{2}{*}{$P$-values } \\
\hline & $N$ & $\%$ & $N$ & $\%$ & $N$ & $\%$ & $N$ & $\%$ & \\
\hline Sex & & & & & & & & & 0.402 \\
\hline Men & 1359 & 54.8 & 1300 & 55.8 & 1683 & 54.6 & 18176 & 55.5 & \\
\hline Women & 1122 & 45.2 & 1029 & 44.2 & 1398 & 45.4 & 14546 & 44.5 & \\
\hline Age & & & & & & & & & 0.001 \\
\hline$<61$ & 523 & 21.1 & 482 & 20.7 & 508 & 16.5 & 5865 & 17.9 & \\
\hline $61-69$ & 475 & 19.1 & 452 & 19.4 & 672 & 21.8 & 7200 & 22.0 & \\
\hline 70-79 & 712 & 28.7 & 641 & 27.5 & 893 & 29.0 & 9418 & 28.8 & \\
\hline$\geqslant 79$ & 771 & 31.1 & 754 & 32.4 & 1008 & 32.7 & 10239 & 31.3 & \\
\hline Topography & & & & & & & & & $<0.001$ \\
\hline Right colon & 765 & 30.8 & 740 & 31.8 & 1024 & 33.2 & 8881 & 27.1 & \\
\hline Left colon & 715 & 28.8 & 717 & 30.8 & 923 & 30.0 & 7917 & 24.2 & \\
\hline Unknown colon ${ }^{a}$ & 65 & 2.6 & 18 & 0.8 & 7 & 0.2 & 2879 & 8.8 & \\
\hline Rectosigmoid junction & 235 & 9.5 & 355 & 15.2 & 326 & 10.6 & 3269 & 10.0 & \\
\hline Rectum & 701 & 28.3 & 499 & 21.4 & 801 & 26.0 & 9776 & 29.9 & \\
\hline Duke's stage & & & & & & & & & $<0.001$ \\
\hline$A$ & 390 & 15.7 & 409 & 17.6 & 567 & 18.4 & 3724 & 11.4 & \\
\hline B & 676 & 27.2 & 713 & 30.6 & 872 & 28.3 & 8567 & 26.2 & \\
\hline C & 592 & 23.9 & 477 & 20.5 & 657 & 21.3 & 7686 & 23.5 & \\
\hline 'D' & 644 & 26.0 & 543 & 23.3 & 743 & 24.1 & 7234 & 22.1 & \\
\hline Unstaged & 179 & 7.2 & 187 & 8.0 & 242 & 7.9 & 5511 & 16.8 & \\
\hline Year of diagnosis & & & & & & & & & 0.007 \\
\hline 1997 & 287 & 11.6 & 267 & 11.5 & 393 & 12.8 & 3782 & 11.6 & \\
\hline 1998 & 305 & 12.3 & 258 & 11.1 & 389 & 12.6 & 4079 & 12.5 & \\
\hline 1999 & 300 & 12.1 & 287 & 12.3 & 351 & 11.4 & 4143 & 12.7 & \\
\hline 2000 & 308 & 12.4 & 280 & 12.0 & 418 & 13.6 & 4185 & 12.8 & \\
\hline 2001 & 304 & 12.3 & 267 & 11.5 & 374 & 12.1 & 4069 & 12.4 & \\
\hline 2002 & 299 & 12.1 & 296 & 12.7 & 356 & 11.6 & 4191 & 12.8 & \\
\hline 2003 & 345 & 13.9 & 324 & 13.9 & 416 & 13.5 & 4096 & 12.5 & \\
\hline 2004 & 333 & 13.4 & 350 & 15.0 & 384 & 12.5 & 4177 & 12.8 & \\
\hline $\begin{array}{l}\text { Surgical resection within } 6 \text { months } \\
\text { since diagnosis }\end{array}$ & & & & & & & & & $<0.001$ \\
\hline Yes & 2065 & 83.2 & 1944 & 83.5 & 2592 & 84.1 & 23908 & 73.1 & \\
\hline No & 416 & 16.8 & 385 & 16.5 & 489 & 15.9 & 8814 & 26.9 & \\
\hline Chemotherapy & & & & & & & & & $<0.001$ \\
\hline Yes & 905 & 36.5 & 751 & 32.2 & 1069 & 34.7 & 8542 & 26.1 & \\
\hline No & 1559 & 62.8 & 1564 & 67.2 & 1982 & 64.3 & 24180 & 73.9 & \\
\hline Unknown & 17 & 0.7 & 14 & 0.6 & 30 & 1.0 & 0 & 0.0 & \\
\hline Radiotherapy & & & & & & & & & $<0.001$ \\
\hline Yes & 375 & 15.1 & 374 & 16.1 & 586 & 19.0 & 4027 & 12.3 & \\
\hline No & 2095 & 84.4 & 1943 & 83.4 & 2467 & 80.1 & 28695 & 87.7 & \\
\hline Unknown & 11 & 0.4 & 12 & 0.5 & 28 & 0.9 & 0 & 0.0 & \\
\hline
\end{tabular}

StataCorp LP) and the user-written Stata command ice (Royston, 2009). All results presented are based on multiple imputations. To test the robustness of our results, all analyses were repeated on complete case analysis since the relevance of this method depends on the missingness mechanism.

\section{RESULTS}

Management. The distribution of year of diagnosis and sex did not differ between the cancer registries (Table 1), although the proportion of right colon cancers was higher in England than in France. Distribution of stage before and after multiple imputations is presented in Table 2. For all cancer localisations, the proportion of patients diagnosed at 'Duke's D' increased in both countries after multiple imputations from $27.3 \%$ to $30.0 \%$ in France and from $27.9 \%$ to $32.7 \%$ in England for patients diagnosed with colon cancer, and from $24.0 \%$ to $31.6 \%$ in France and from $23.2 \%$ to $28.4 \%$ in England for patients diagnosed with rectal cancer. Treatment modalities (chemotherapy, radiotherapy and surgical resection with curative intent within 6 months since diagnosis) differed between the countries. Such surgical resections were performed more frequently in France, being used in $83.6 \%$ of 
Table 2. Distribution of Duke's stage before and after multiple imputation by site and country of residence

\begin{tabular}{|c|c|c|c|c|c|c|c|c|}
\hline & \multicolumn{4}{|c|}{ Complete case analysis } & \multicolumn{4}{|c|}{ Multiple imputation } \\
\hline & \multicolumn{2}{|l|}{ France } & \multicolumn{2}{|c|}{ England } & \multicolumn{2}{|c|}{ France } & \multicolumn{2}{|c|}{ England } \\
\hline & Colon (\%) & Rectum (\%) & Colon (\%) & Rectum (\%) & Colon (\%) & Rectum (\%) & Colon (\%) & $\begin{array}{l}\text { Rectum } \\
(\%)\end{array}$ \\
\hline Duke's A & 14.9 & 31.7 & 10.4 & 22.1 & 14.3 & 27.2 & 9.7 & 19.2 \\
\hline Duke's B & 33.3 & 23.4 & 34.0 & 25.1 & 31.9 & 21.0 & 31.0 & 23.7 \\
\hline Duke's C & 24.5 & 20.9 & 27.7 & 29.6 & 23.7 & 20.2 & 26.6 & 28.7 \\
\hline 'Duke's D' & 27.2 & 24.0 & 27.9 & 23.2 & 30.0 & 31.5 & 32.7 & 28.4 \\
\hline
\end{tabular}

French patients vs $73.1 \%$ in England. No matter what stage at diagnosis or tumour localisation, the rate of patients receiving a surgical resection with curative intent within 6 months was higher in France than in England. This difference was limited for localised colon cancer (98.9\% in France $v s$ 96.1\% in England for stage A; 99.0\% in France vs $96.3 \%$ in England for stage B) and more pronounced for advanced colon cancer $(97.6 \%$ in France $v s 87.8$ in England for stage C; $52.4 \%$ in France $v s$ 32.3\% in England for stage 'D'). Concerning rectal cancer, the difference in the rate of patients with surgical resection within 6 months increased with stage (97.6\% in France $v s$ 93.2\% in England for stage A; $94.6 \%$ in France vs $87.6 \%$ in England for stage B; $86.7 \%$ in France vs 80.8 in England for stage C; $32.6 \%$ in France vs $22.8 \%$ in England for stage 'D').

Survival. The association between country of residence and relative survival was not constant over time since diagnosis. In survival analysis, the interaction between time since diagnosis and country of residence was statistically significant $(P<0.001)$, with the gain in survival for French patients decreasing with time since diagnosis. Therefore, multivariable models were stratified according to time since diagnosis (first year since diagnosis $v s$ first to fifth year since diagnosis).

One-year survival analyses for patients diagnosed with colon cancer. Patients diagnosed with colon cancer living in France had a better prognosis than those living in England for the first year after diagnosis $(\mathrm{EHR}=0.70(0.66-0.75))$ (Table 3, model 1). After adjustment for sex, age and period of diagnosis, the higher survival for French patients remained unchanged $(\mathrm{EHR}=0.70(0.65-0.74))$ (Table 3, model 2). After successive adjustment for tumour site (Table 3, model 3) and stage at diagnosis (Table 3, model 4), patients living in France still had a higher 1-year survival than those living in England $(\mathrm{EHR}=0.68(0.64-0.74)$ ).

To investigate the influence of treatment, survival analyses were conducted separately on localised cancer (Duke's A and Duke's B) and advanced cancer (Duke's C and 'Duke's D'). In unadjusted analyses, French patients diagnosed with a localised colon cancer had a better survival than those diagnosed in England $(\mathrm{EHR}=0.77$ $(0.65-0.93))$ (Table 3, model 5a). Differences in survival decreased after adjusting for surgical resection with curative intent within 6 months, but country of residence was still associated with 1-year survival $(\mathrm{EHR}=0.82(0.68-0.99), P=0.038)$ (Table 3, model 6a). French patients diagnosed with an advanced colon cancer also had better survival than those diagnosed in England $(\mathrm{EHR}=0.67$ $(0.63-0.72)$ ) (Table 3, model 5b) in unadjusted analyses. After adjustment for surgery with curative intent, country of residence remained associated with 1-year survival for patients diagnosed with an advanced colon cancer $(\mathrm{EHR}=0.79(0.74-0.85))$ (Table 3, model $6 \mathrm{~b}$ ). After taking into account the use of chemotherapy, country of residence was no more associated with 1-year survival $(\mathrm{EHR}=0.99(0.92-1.01), P=0.095)$ (Table 3, model 7b). After considering the interaction, country of residence was associated with survival only in the presence of chemotherapy $(\mathrm{EHR}=0.99$
(0.92-1.07), $\quad P=0.918)$ in absence of chemotherapy and $($ EHR $=0.81(0.69-0.94), P=0.008)$ in presence of chemotherapy) (Table 3, model 8b).

One-year survival analyses for patients diagnosed with rectum cancer. Similarly, after adjustment for age, sex, period of diagnosis and stage, French rectal cancer patients had a better 1-year-survival than English patients $(\mathrm{EHR}=0.76(0.68-0.86)$ ) (Table 3, model 11 ). Country of residence was significantly associated with 1 -year survival for patients diagnosed with a localised cancer $(\mathrm{EHR}=0.70$ (0.49-0.99), $P=0.048$ ) (Table 3, model 11a). But, again, after further adjustment for surgical resection with curative intent, country of residence was no longer statistically significant $($ EHR $=0.74(0.51-1.08))($ Table 3, model 12a) .

When the analysis was restricted to include patients with advanced rectal cancer only, 1-year survival remained higher in France $(\mathrm{EHR}=0.69(0.61-0.77)) \quad($ Table 3, model 11b). After taking into account the surgical resection with curative intent and radiochemotherapy, country of residence was no longer associated with 1 -year survival $(\mathrm{EHR}=0.96(0.85-1.09), P=0.2372)$ (Table 3, model 13b).

Patients diagnosed with colon cancer who had survived at least 1 year. Among colon cancer patients longer term ( $2-5$ years) excess hazards of death were comparable in both countries even after adjusting for age, sex, tumour localisation and year of diagnosis $(\mathrm{EHR}=1.02(0.95-1.11))$ (Table 4, model 3). However, adjustment for stage at diagnosis shows that these patients had a better survival in France than in England $(\mathrm{EHR}=0.92(0.85-0.99), P=0.016)$ (Table 4 , model 4$)$. Longer term (2-5 years) excess hazards of death were comparable in both countries either for localised colon cancer $(\mathrm{EHR}=1.05(0.85-1.31))$ (Table 4, model 5a) or for advanced colon cancer $(\mathrm{EHR}=1.03(0.95-1.12))$ (Table 4, model 5b).

Patients diagnosed with rectum cancer who had survived at least 1 year. Similarly, longer term (2-5 years) excess hazards of death for rectal cancer patients were comparable in both countries after adjusting for age, sex and stage at diagnosis $(\mathrm{EHR}=0.91(0.81-$ 1.03)) (Table 4, model 11). However, English patients diagnosed with an advanced rectum cancer had a better long-term survival than those living in France $(\mathrm{EHR}=1.17(1.03-1.31)$ ) (Table 4, model 11b). After adjustment for surgical resection with curative intent, longer term (2-5 years) excess hazards of death were comparable in both countries $(\mathrm{EHR}=1.06(0.93-1.21))$ (Table 4, model 12b).

Complete case analysis results. As discussed in Materials and methods, all survival analyses were repeated in the framework of complete case analysis (Tables 3 and 4). The results of these analyses were comparable to those performed using multiple imputation and are therefore not repeated here. The only exception concerned the influenced of treatment variables (surgical resection with curative intent, chemotherapy and radiotherapy) on the 
Table 3. Excess hazard ratios of death for country of residence during the first year since diagnosis, colorectal cancer, 1997-2004

Multiple imputations for missing values

\begin{tabular}{|l|l|l|l|l|l|l|l|l|l}
\hline $\mathbf{N}$ & Variable & EHR & $\mathbf{9 5 \%} \mathrm{Cl}$ & $\boldsymbol{P}$-values & EHR & $95 \% \mathrm{Cl}$ & $\boldsymbol{P}$-values \\
\hline Colon cancer &
\end{tabular}

Model 1

\begin{tabular}{|c|c|c|c|c|c|c|c|c|c|c|}
\hline & Countries & England & 1.00 & & & $<0.001$ & 1.00 & & & $<0.001$ \\
\hline & & France & 0.70 & 0.66 & 0.75 & & 0.73 & 0.68 & 0.78 & \\
\hline \multirow[t]{3}{*}{ Model 2} & $=$ Model $1+$ age, sex, period & & & & & & & & & \\
\hline & & England & 1.00 & & & $<0.001$ & 1.00 & & & $<0.001$ \\
\hline & & France & 0.70 & 0.65 & 0.74 & & 0.73 & 0.68 & 0.78 & \\
\hline \multirow{3}{*}{ Model 3} & 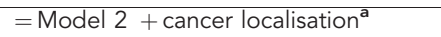 & & & & & & & & & \\
\hline & & England & 1.00 & & & $<0.001$ & 1.00 & & & $<0.001$ \\
\hline & & France & 0.70 & 0.65 & 0.74 & & 0.81 & 0.75 & 0.86 & \\
\hline \multirow[t]{3}{*}{ Model 4} & $=$ Model $3+$ stage & & & & & & & & & \\
\hline & & England & 1.00 & & & $<0.001$ & 1.00 & & & $<0.001$ \\
\hline & & France & 0.68 & 0.64 & 0.74 & & 0.75 & 0.70 & 0.80 & \\
\hline \multirow[t]{3}{*}{ Model $5 a$} & $=$ Model 2 for Duke's A \& B only & & & & & & & & & \\
\hline & & England & 1.00 & & & 0.006 & 1.00 & & & 0.033 \\
\hline & & France & 0.77 & 0.65 & 0.93 & & 0.79 & 0.66 & 0.95 & \\
\hline \multirow[t]{3}{*}{ Model $6 a$} & $\begin{array}{l}=\text { Model } 5 \text { a for Duke's A \& } \\
B+\text { resection within } 6 \text { months }\end{array}$ & & & & & & & & & \\
\hline & & England & 1.00 & & & 0.038 & 1.00 & & & 0.038 \\
\hline & & France & 0.82 & 0.68 & 0.99 & & 0.82 & 0.68 & 0.98 & \\
\hline \multirow[t]{3}{*}{ Model 5b } & $=$ Model 3 for Duke's C \& D cancer only & & & & & & & & & \\
\hline & & England & 1.00 & & & $<0001$ & 1.00 & & & $<0.001$ \\
\hline & & France & 0.67 & 0.63 & 0.72 & & 0.74 & 0.69 & 0.80 & \\
\hline \multirow[t]{3}{*}{ Model 6b } & $\begin{array}{l}=\text { Model } 5 b \text { for Duke's C \& D cancer } \\
\text { only + resection within } 6 \text { months }\end{array}$ & & & & & & & & & \\
\hline & & England & 1.00 & & & $<0.001$ & 1.00 & & & $<0.001$ \\
\hline & & France & 0.79 & 0.74 & 0.85 & & 0.83 & 0.77 & 0.90 & \\
\hline \multirow[t]{3}{*}{ Model 7b } & $\begin{array}{l}=\text { model } 5 b \text { for Duke's C \& D cancer } \\
\text { only + resection within } 6 \\
\text { months + chemotherapy }\end{array}$ & & & & & & & & & \\
\hline & & England & 1.00 & & & 0.095 & 1.00 & & & 0.862 \\
\hline & & France & 0.94 & 0.88 & 1.01 & & 1.00 & 0.92 & 1.06 & \\
\hline Model 8b & $\begin{array}{l}=\text { Model } 5 b \text { for Duke's C \& D cancer } \\
\text { only + resection within } 6 \text { months }+ \\
\text { chemotherapy }+ \text { interaction } \\
\text { (countries-chemotherapy) }\end{array}$ & & & & & & & & & \\
\hline \multirow[t]{2}{*}{$\begin{array}{l}\text { Without } \\
\text { chemotherapy }\end{array}$} & & England & 1.00 & & & 0.918 & 1.00 & & & 0.082 \\
\hline & & France & 0.99 & 0.92 & 1.07 & & 1.07 & 0.99 & 1.17 & \\
\hline \multirow{2}{*}{$\begin{array}{l}\text { With } \\
\text { chemotherapy }\end{array}$} & & England & 1.00 & & & 0.008 & 1.00 & & & 0.001 \\
\hline & & France & 0.81 & 0.69 & 0.94 & & 0.76 & 0.65 & 0.89 & \\
\hline \multicolumn{11}{|c|}{ Rectum cancer } \\
\hline \multirow[t]{2}{*}{ Model 9} & & England & 1.00 & & & $<0.001$ & 1.00 & & & $<0.001$ \\
\hline & & France & 0.76 & 0.68 & 0.86 & & 0.74 & 0.64 & 0.85 & \\
\hline \multirow[t]{3}{*}{ Model 10} & $=$ Model $9+$ age, sex, period & & & & & & & & & \\
\hline & & England & 1.00 & & & $<0.001$ & 1.00 & & & $<0.001$ \\
\hline & & France & 0.76 & 0.67 & 0.85 & & 0.73 & 0.63 & 0.84 & \\
\hline \multirow[t]{3}{*}{ Model 11} & $=$ Model $10+$ stage & & & & & & & & & \\
\hline & & England & 1.00 & & & $<0.001$ & 1.00 & & & $<0.001$ \\
\hline & & France & 0.69 & 0.61 & 0.77 & & 0.67 & 0.58 & 0.77 & \\
\hline \multirow[t]{3}{*}{ Model 11a } & $\begin{array}{l}=\text { Model } 10 \text { for duke's A \& B cancer } \\
\text { only }\end{array}$ & & & & & & & & & \\
\hline & & England & 1.00 & & & 0.048 & 1.00 & & & 0.065 \\
\hline & & France & 0.70 & 0.49 & 0.99 & & 0.71 & 0.50 & 1.02 & \\
\hline \multirow[t]{3}{*}{ Model 12a } & $\begin{array}{l}=\text { Model } 10 \text { for Duke's A \& B cancer } \\
\text { only }+ \text { resection within } 6 \text { months }\end{array}$ & & & & & & & & & \\
\hline & & England & 1.00 & & & 0.13 & 1.00 & & & 0.353 \\
\hline & & France & 0.74 & 0.51 & 1.08 & & 0.83 & 0.57 & 1.22 & \\
\hline
\end{tabular}




\begin{tabular}{|c|c|c|c|c|c|c|c|c|c|c|}
\hline \multirow{3}{*}{$\begin{array}{l}\mathbf{N} \\
\text { Model 11b }\end{array}$} & \multirow{2}{*}{\multicolumn{2}{|c|}{ Variable }} & \multicolumn{3}{|c|}{$\begin{array}{l}\text { Multiple imputations for } \\
\text { missing values }\end{array}$} & \multicolumn{5}{|c|}{ Complete case analysis ${ }^{a}$} \\
\hline & & & \multirow[t]{2}{*}{ EHR } & \multirow[t]{2}{*}{$95 \% \mathrm{Cl}$} & \multirow[t]{2}{*}{$P$-values } & \multicolumn{2}{|c|}{ EHR } & \multicolumn{2}{|c|}{$95 \% \mathrm{Cl}$} & \multirow[t]{2}{*}{$P$-values } \\
\hline & $\begin{array}{l}=\text { Model } 10 \text { for Duke's C \& D cancer } \\
\text { only }\end{array}$ & & & & & & & & & \\
\hline & & England & 1.00 & & & $<0.001$ & 1.00 & & & $<0.001$ \\
\hline & & France & 0.69 & 0.61 & 0.77 & & 0.66 & 0.57 & 0.77 & \\
\hline \multirow[t]{3}{*}{ Model 12b } & $\begin{array}{l}=\text { Model } 11 \text { a for Duke's C \& D cancer } \\
\text { only + resection within } 6 \text { months }\end{array}$ & & & & & & & & & \\
\hline & & England & 1.00 & & & $<0.001$ & 1.00 & & & $<0.001$ \\
\hline & & France & 0.73 & 0.64 & 0.82 & & 0.77 & 0.66 & 0.89 & \\
\hline \multirow[t]{3}{*}{ Model 13b } & $\begin{array}{l}=\text { Model } 11 \text { a for Duke's C \& D cancer } \\
\text { only + resection within } 6 \\
\text { months + radiotherapy }+ \\
\text { chemotherapy }\end{array}$ & & & & & & & & & \\
\hline & & England & 1.00 & & & 0.575 & 1.00 & & & 0.637 \\
\hline & & France & 0.96 & 0.85 & 1.09 & & 1.01 & 0.86 & 1.10 & \\
\hline
\end{tabular}

longer term (2-5 years) excess hazards of death for patients diagnosed with an advanced rectum cancer. In the Framework of complete case analyses, patients living in England still had a better survival than French patients (Table 4, models 5b, 6b and 7b).

\section{DISCUSSION}

This study confirms that over the study period 5-year colon and rectal cancer survival was higher in France than in England. This difference was primarily due to a larger proportion of English patients dying within the first year after their diagnosis and if an individual survived a year after their diagnosis then the difference in survival between the countries was no longer statistically significant. This study also demonstrates differences in the management of patients between the countries with surgery being used significantly less frequently in England compared with France, these different surgery proportions being related to the survival difference observed.

Potential differences between the data sets collected in each country need to be considered. Indeed, the lack of detail on types of surgery undertaken in the English registry data forced us to limit it to surgical resection with curative intent undertaken within the first 6 months after the diagnosis. Similarly, the French registries captured information on all chemotherapy and radiotherapy administered irrespective of intent whereas NYCRIS did not. Efforts have been made to address these differences in these analyses by attempting to limit the French treatment information included to that comparable to the English data. But, for future analyses, it would be highly desirable to have more detailed treatment data sets that included information on these factors to enable more robust comparisons.

Likewise, differences may exist in the English and French data sets in relation to other important variables such as stage. The NYCRIS aims to collect stage at diagnosis and as neo-adjuvant treatments can downstage rectal tumours those receiving them were classified as 'not staged'. In addition, accurate staging requires accurate pathological assessment of a resected tumour specimen. The NYCRIS had a lower proportion of major resection, so a lower proportion of resected specimens and, therefore, a lower proportion of patients in which a robust stage could be captured. The recording of stage improved considerably in the NYCRIS data from
1998 onwards (registry merger in 1997). To test if our findings were influenced by this change, an analysis restricted to 1998-2004 data was conducted which provided similar findings (results not presented).

Missing data multiple imputation was undertaken in our study to deal with missing values (Nur et al, 2010). Unfortunately, given the reasons for the lower staging proportion in England compared with France, the missing values for stage at diagnosis were probably not missing at random (i.e., patients with missing stage tend to have a more advanced disease than others), which could reduce the robustness of our results since the effect of the absence of treatment in survival could be underestimated. But, to our knowledge, no unbiased method exists for taking into account missing values not at random.

Another limitation of this study is the small proportion of the French population covered by the French digestive cancer registries (3\% of the whole national population), while NYCRIS data represent $13.3 \%$ of the national population of England. Such a limitation is usual for population-based studies in France since information on stage at diagnosis and treatment are not routinely available in all French cancer registries but only in specialised cancer registries. The three specialised digestive cancer registries in France are located in Calvados, Côte d'Or and Saone et Loire, these areas being mainly rural, two of them having a reference cancer centre (University hospital and cancer care centre) in their regional capital. It is noteworthy that French colorectal cancer 1- and 5-year relative survival calculated in this study was very closed to those estimated on all French cancer registries, which cover about $17 \%$ of the French population (Bossard et al, 2007).

In a previous study, the difference in observed survival between Europe and America was mainly explained by the stage at diagnosis (Gatta et al, 2000). Our study does not give such importance to stage at diagnosis in explaining the difference in relative survival between England and France. In a more recent study of relative survival which included 10 European cancer registries (from Italy, France, Netherlands, Spain and UK) and 9 US cancer registries, the role of surgical practices (curative resection) appeared to be as important as stage at diagnosis (Ciccolallo et al, 2005). In 1990, a randomised trial reported that chemotherapy improved survival for stage III colon cancer (Moertel et al, 1990). European guidelines for the management of colon cancer also recommended the prescription of adjuvant chemotherapy for stage II colon cancer for which the number of 
Table 4. Excess hazard ratios of death for country of residence after the first year since diagnosis (2-5 years), colorectal cancer, 1997-2004

Multiple imputations for missing

\section{$N$}

Colon cancer

Model 1

\begin{tabular}{|c|c|}
\hline & Countries \\
\hline Model 2 & $=$ Model $1+$ age, sex, period \\
\hline Model 3 & $=$ Model $2+$ cancer localisation \\
\hline Model 4 & $=$ Model $3+$ stage \\
\hline Model $5 a$ & $=$ Model 3 for Duke's A \& B cancer only \\
\hline Model $6 a$ & $\begin{array}{l}=\text { Model } 5 \text { a for Duke's A \& B cancer } \\
\text { only }+ \text { resection within } 6 \text { months }\end{array}$ \\
\hline Model $5 b$ & $\begin{array}{l}=\text { Model } 3 \text { for Duke's C \& D cancer } \\
\text { only }\end{array}$ \\
\hline Model 6b & $\begin{array}{l}=\text { Model } 5 b \text { for Duke's C \& D cancer } \\
\text { only + resection surgery within } 6 \\
\text { months }\end{array}$ \\
\hline & \\
\hline & \\
\hline
\end{tabular}

\section{Rectum cancer}

\begin{tabular}{|l|l|} 
& \\
\hline & \\
\hline Model 10 & $=$ Model 9 + age, sex, period
\end{tabular}

\begin{tabular}{|l|l}
\hline & $=$ Model $9+$ age, sex, period \\
\hline Model 11 & $=$ Model $10+$ stage \\
\hline
\end{tabular}

\begin{tabular}{|c|c|}
\hline$\Lambda$ & Variab \\
\hline \multicolumn{2}{|c|}{ Colon canc } \\
\hline \multicolumn{2}{|c|}{ Model } \\
\hline & Countrie \\
\hline Model & $=$ Model \\
\hline Model & = Model \\
\hline Model & $=$ Model \\
\hline Model 5 & $=$ Model \\
\hline Model 6 & $\begin{array}{l}=\text { Model } \\
\text { only }+ \text { res }\end{array}$ \\
\hline Model 5 & $\begin{array}{l}=\text { Model } \\
\text { only }\end{array}$ \\
\hline Model 6 & $\begin{array}{l}\text { = Model } \\
\text { only + rese } \\
\text { months }\end{array}$ \\
\hline Rectum & \\
\hline Model & \\
\hline Model 1 & $=$ Model \\
\hline Model 1 & $=$ Model \\
\hline Model 1 & $=$ Model \\
\hline
\end{tabular}

\begin{tabular}{|l|l}
\hline Model 11a & = Model 9 for Duke's A \& B cancer only \\
\hline Model 11b & $\begin{array}{l}\text { = Model 11a for Duke's C \& D cancer } \\
\text { only }\end{array}$
\end{tabular}

Model 12b $\quad$ = Model 11a for Duke's C \& D cancer only + resection within 6 months

Model 13b $=$ Model 12a for Duke's C \& D cancer only + radiotherapy + chemotherapy

Abbreviations: $\mathrm{Cl}=$ confidence interval; $\mathrm{EHR}=$ excess hazard ratio

a Unknown colon cancer (C18.8 or C18.9) was kept in complete case analysis values

\section{Complete case analysis ${ }^{a}$}

\begin{tabular}{|l|c|c|l|l|l|}
\hline EHR & $95 \% \mathrm{Cl}$ & $P$-values & EHR & $95 \% \mathrm{Cl}$ & $P$-values \\
\hline
\end{tabular}

\begin{tabular}{|l|l|l|l|l|l|l|l|l|}
\hline England & 1.00 & & & 0.571 & 1.00 & & & 0.407 \\
\hline France & 1.02 & 0.95 & 1.11 & & 1.03 & 0.95 & 1.11 & \\
\hline England & 1.00 & & & & & & & \\
\hline France & 1.03 & 0.95 & 1.11 & & 1.03 & 0.95 & 1.12 & 0.458 \\
\hline & & & & & & & & \\
\hline England & 1.00 & & & 0.472 & 1.00 & & & 0.414 \\
\hline France & 1.03 & 0.95 & 1.11 & & 1.03 & 0.95 & 1.12 & \\
\hline & & & & & & & & \\
\hline England & 1.00 & & & 0.032 & 1.00 & & & 0.036 \\
\hline France & 0.92 & 0.85 & 0.99 & & 0.92 & 0.85 & 0.99 & \\
\hline & & & & & & & & \\
\hline England & 1.00 & & & 0.623 & 1.00 & & & 0.829 \\
\hline France & 1.05 & 0.85 & 1.31 & & 1.02 & 0.82 & 1.28 & \\
\hline & & & & & & & & \\
\hline England & 1.00 & & & 0.318 & 1.00 & & & 0.737 \\
\hline France & 1.07 & 0.86 & 1.33 & & 1.04 & 0.84 & 1.30 & \\
\hline & & & & & & & & \\
\hline England & 1.00 & & & 0.449 & 1.00 & & & 0.199 \\
\hline France & 1.03 & 0.95 & 1.12 & & 1.06 & 0.97 & 1.15 & \\
\hline & & & & & & & & \\
\hline England & 1.00 & & & 0.25 & 1.00 & & & 0.449 \\
\hline France & 1.04 & 0.97 & 1.14 & & 1.03 & 0.95 & 1.12 & \\
\hline
\end{tabular}

\begin{tabular}{|c|c|c|c|c|c|c|c|c|}
\hline England & 1.00 & & & 0.733 & 1.00 & & & 0.891 \\
\hline France & 0.98 & 0.87 & 1.10 & & 1.01 & 0.90 & 1.14 & \\
\hline England & 1.00 & & & 0.807 & 1.00 & & & 0.829 \\
\hline France & 0.99 & 0.88 & 1.11 & & 1.01 & 0.89 & 1.15 & \\
\hline England & 1.00 & & & 0.127 & 1.00 & & & 0.542 \\
\hline France & 0.91 & 0.81 & 1.03 & & 1.04 & 0.92 & 1.18 & \\
\hline England & 1.00 & & & 0.161 & 1.00 & & & 0.734 \\
\hline France & 0.81 & 0.60 & 1.09 & & 0.89 & 0.45 & 1.76 & \\
\hline England & 1.00 & & & 0.011 & 1.00 & & & $<0.001$ \\
\hline France & 1.17 & 1.03 & 1.31 & & 1.36 & 1.19 & 1.56 & \\
\hline England & 1.00 & & & 0.331 & 1.00 & & & $<0.001$ \\
\hline France & 1.06 & 0.93 & 1.21 & & 1.39 & 1.22 & 1.60 & \\
\hline England & 1.00 & & & 0.218 & 1.00 & & & $<0.001$ \\
\hline France & 1.09 & 0.95 & 1.24 & & 1.45 & 1.26 & 1.66 & \\
\hline
\end{tabular}


lymph sampling is $<12$, the tumours are poorly differentiated, vascular or lymphatic or perineural invasion has occurred, or presentation is emergency and at pT4 stage (Labianca et al, 2010). Chemotherapy is also recommended for metastatic colon and rectum tumours. Studies comparing adjuvant therapy uptake between countries are rare because such detailed data are not usually available at a population level. Nevertheless, a recent study highlights that proportions of adjuvant therapies differed notably between European areas for either stage II or stage III tumours (Gatta et al, 2010). For example, $60.6 \%$ of patients diagnosed with stage II colon cancer received adjuvant chemotherapy in Slovakia and only $5.3 \%$ of such patients received adjuvant therapy in Estonia. Our study confirms that this variation chemotherapy uptake across countries could be a potential explanation of difference in 1-year survival of advanced colon cancer.

If differences in data quality can be dismissed, then the lower treatment proportions and their relationship to survival must be real. What is not apparent from the results is, however, why the treatment proportions in England are lower. There are two potential explanations that could account for this. First, it may be that there are fundamental differences in the characteristics of the two general populations that make fewer English patients eligible for active treatments. For example, English people, including cancer patients, may have a higher prevalence and/or severity of co-morbid disease that limits how these treatments could be employed.

A second alternative explanation maybe, however, that there were real differences in the overall management of the cancer patients between the countries during this time period. Such a difference in treatment could partly be explained by differences in medical practices and/or in patient behaviour. Since indication for surgery was clearly defined by international guidelines, there is no reason to suppose that the practice of an English surgeon would differ to a French one for a given patient. Instead, health-care system organisation offers a likely explanation for this difference in surgery indication. Indeed, therapeutic delay (time since diagnosis to first treatment) is notably longer in England (Robertson et al, 2004) compared with France (Dejardin et al, 2004) even if this topic remains poorly investigated in France. Nevertheless, the influence of therapeutic delay on survival is highly controversial (Ramos et al, 2007) and, thus, is likely to explain only a part of this difference. Beside medical practices, patient behaviour towards diseases could differ between France and England. Indeed, time from first symptom to diagnosis, as well as time from diagnosis to staging is influenced by behaviour towards symptoms (Mitchell et al, 2008), and therefore could influence the distribution of stage between the countries. While this study suggests that stage at diagnosis has no impact on the inter-country gap in survival, we cannot exclude the possibility that English patients had more comorbidities than French ones for a given stage at diagnosis. Further studies are needed to investigate this additional potential explanation for the gap in survival.

During the period study, major reforms were initiated with the publication of national cancer plans in England in 2000 (Health Do, 2000) and in France in 2003 (available online at http:// www.plan-cancer.gouv.fr/). A recent study highlights some beneficial impact of NHS cancer plan in England. For example, the 3 -year relative survival for colon cancer increased from 53.5\% during the periods $1996-2000$ to $57.6 \%$ for the periods $2004-2006$ (Rachet et al, 2009). Since survival data are not yet published for France, we cannot compare the effectiveness of the French and English cancer plan.

Every effort to investigate the reasons for the disparities we have observed between these two countries, and more generally across Europe, should be encouraged. Improved collection and standardisation of additional variables such as co-morbidity, anaesthetic risk and treatment pathways may be crucial for a better understanding of underlying mechanisms of inter-country differences in survival of patients with cancer.

\section{ACKNOWLEDGEMENTS}

We thank the French National Cancer Institute and the 'Fondation de France', which provided financial support for this study. BR and EM are supported by Cancer Research UK (C1336/A5735 and C23434/A9805, respectively).

\section{REFERENCES}

Abdel-Rahman M, Stockton D, Rachet B, Hakulinen T, Coleman MP (2009) What if cancer survival in Britain were the same as in Europe: how many deaths are avoidable? Br J Cancer 101(Suppl 2): S115-S124.

Beral V, Peto R (2010) UK cancer survival statistics. BMJ 341: c4112.

Berrino F, De Angelis R, Sant M, Rosso S, Bielska-Lasota M, Lasota MB, Coebergh JW, Santaquilani M (2007) Survival for eight major cancers and all cancers combined for European adults diagnosed in 1995-99: results of the EUROCARE-4 study. Lancet Oncol 89: 773-783.

Bossard N, Velten M, Remontet L, Belot A, Maarouf N, Bouvier AM, Guizard AV, Tretarre B, Launoy G, Colonna M, Danzon A, Molinie F, Troussard X, Bourdon-Raverdy N, Carli PM, Jaffre A, Bessaguet C, Sauleau E, Schvartz C, Arveux P, Maynadie M, Grosclaude P, Esteve J, Faivre J (2007) Survival of cancer patients in France: a population-based study from the Association of the French Cancer Registries (FRANCIM). Eur J Cancer 43(1): 149-160.

Brenner H, Bouvier AM, Foschi R, Hackl M, Larsen IK, Lemmens V, Mangone L, Francisci S. Group tEW (2011) Progress in colorectal cancer survival in Europe, from the late 1980s to the early 21st century: The EUROCARE study. Int J Cancer 131: 1649-1658.

Ciccolallo L, Capocaccia R, Coleman MP, Berrino F, Coebergh JWW, Damhuis RAM, Faivre J, Martinez-Garcia C, Moller H, de Leon MP, Launoy G, Raverdy N, Williams EMI, Gatta G (2005) Survival differences between European and US patients with colorectal cancer: role of stage at diagnosis and surgery. Gut 54(2): 268-273.

Coleman MP, Quaresma M, Berrino F, Lutz JM, De Angelis R, Capocaccia R, Baili P, Rachet B, Gatta G, Hakulinen T, Micheli A, Sant M, Weir HK, Elwood JM, Tsukuma H, Koifman S, E Silva GA, Francisci S, Santaquilani M, Verdecchia A, Storm HH, Young JL (2008) Cancer survival in five continents: a worldwide population-based study (CONCORD). Lancet Oncol 98: 730-756.

Dejardin O, Herbert C, Velten M, Buemi A, Menegoz F, Maarouf N, Launoy G (2004) Social and geographical factors influencing the delay in treatment for colorectal cancer. Br J Cancer 91(9): 1751-1752.

Dickman PW, Sloggett A, Hills M, Hakulinen T (2004) Regression models for relative survival. Stat Med 23(1): 51-64.

Dukes C (1932) The classification of cancer of the rectum. J Pathol Bacteriol 35: 9.

Engholm G, Kejs AM, Brewster DH, Gaard M, Holmberg L, Hartley R, Iddenden R, Møller H, Sankila R, Thomson CS, Storm HH (2007) Colorectal cancer survival in the Nordic countries and the United Kingdom: excess mortality risk analysis of 5 year relative period survival in the period 1999 to 2000. Int J Cancer 121(5): 1115-1122.

Folkesson J, Engholm G, Ehrnrooth E, Kejs AM, Påhlman L, Harling H, Wibe A, Gaard M, Thornorvaldur J, Tryggvadottir L, Brewster DH, Hakulinen T, Storm HH (2009) Rectal cancer survival in the Nordic countries and Scotland. Int J Cancer 125(10): 2406-2412.

Fritz A, Percy C, Jack A, Shanmugaratnam K, Sobin L, Dm Parkin, Whelan S (2000) International Classification of Diseases for Oncology. 3rd edn, World Health Organization: Geneva.

Gatta G, Capocaccia R, Sant M, Bell CM, Coebergh JW, Damhuis RA, Faivre J, Martinez-Garcia C, Pawlega J, Ponz de Leon M, Pottier D, Raverdy N, Williams EM, Berrino F (2000) Understanding variations in survival for colorectal cancer in Europe: a EUROCARE high resolution study. Gut 47(4): 533-538.

Gatta G, Zigon G, Aareleid T, Ardanaz E, Bielska-Lasota M, Galceran J, Góźdź S, Hakulinen T, Martinez-Garcia C, Plesko I, Zakelj MP, Rachtan J, Tagliabue G, Vercelli M, Faivre J (2010) Patterns of care for European 
colorectal cancer patients diagnosed 1996-1998: a EUROCARE high resolution study. Acta Oncol 49(6): 776-783.

Health Do (2000) The NHS Cancer PlanHealth Do (ed) (Department of Health: London.

Jones AM, Morris E, Thomas J, Forman D, Melia J, Moss SM (2009) Evaluation of bowel cancer registration data in England, 1996-2004. Br J Cancer 101(8): 1269-1273.

Labianca R, Nordlinger B, Beretta GD, Brouquet A, Cervantes A, Group EGW (2010) Primary colon cancer: ESMO Clinical Practice Guidelines for diagnosis, adjuvant treatment and follow-up. Ann Oncol 21(Suppl 5): v70-v77.

Little R, Rubin D (2002) Statistical Analysis with Missing Data. John Wiley \& Sons, Inc.: Hoboken, New Jersey.

Mitchell E, Macdonald S, Campbell NC, Weller D, Macleod U (2008) Influences on pre-hospital delay in the diagnosis of colorectal cancer: a systematic review. Br J Cancer 98(1): 60-70.

Moertel CG, Fleming TR, Macdonald JS, Haller DG, Laurie JA, Goodman PJ, Ungerleider JS, Emerson WA, Tormey DC, Glick JH (1990) Levamisole and fluorouracil for adjuvant therapy of resected colon carcinoma. $N$ Engl $J$ Med 322(6): 352-358.

Morris EJ, Sandin F, Lambert PC, Bray F, Klint A, Linklater K, Robinson D, Påhlman L, Holmberg L, Møller H (2011) A population-based comparison of the survival of patients with colorectal cancer in England, Norway and Sweden between 1996 and 2004. Gut 60(8): 1087-1093.

Møller H, Richards S, Hanchett N, Riaz SP, Lüchtenborg M, Holmberg L, Robinson D (2011) Completeness of case ascertainment and survival time error in English cancer registries: impact on 1-year survival estimates. $\mathrm{Br} J$ Cancer 105(1): 170-176.
Nur U, Shack LG, Rachet B, Carpenter JR, Coleman MP (2010) Modelling relative survival in the presence of incomplete data: a tutorial. Int $J$ Epidemiol 39(1): 118-128.

Rachet B, Maringe C, Nur U, Quaresma M, Shah A, Woods LM, Ellis L, Walters S, Forman D, Steward J, Coleman MP (2009) Population-based cancer survival trends in England and Wales up to 2007: an assessment of the NHS cancer plan for England. Lancet Oncol 10(4): 351-369.

Ramos M, Esteva M, Cabeza E, Campillo C, Llobera J, Aguiló A (2007) Relationship of diagnostic and therapeutic delay with survival in colorectal cancer: a review. Eur J Cancer 43(17): 2467-2478.

Robertson R, Campbell NC, Smith S, Donnan PT, Sullivan F, Duffy R, Ritchie LD, Millar D, Cassidy J, Munro A (2004) Factors influencing time from presentation to treatment of colorectal and breast cancer in urban and rural areas. Br J Cancer 90(8): 1479-1485.

Royston P (2009) Multiple imputation of missing values: Further update of ice, with an emphasis on categorical variables. STATA J 92: 11.

Rubin D (1987) Multiple Imputation for Nonresponse in Surveys. John Wiley \& Sons: New York.

Woods LM, Coleman MP, Lawrence G, Rashbass J, Berrino F, Rachet B (2011) Evidence against the proposition that 'UK cancer survival statistics are misleading': simulation study with National Cancer Registry data. BMJ 342: d3399.

This work is published under the standard license to publish agreement. After 12 months the work will become freely available and the license terms will switch to a Creative Commons AttributionNonCommercial-Share Alike 3.0 Unported License. 